\title{
On the Quality Construction of Sino-foreign Cooperation Program in China
}

\author{
Haiying Ma \\ School of Economics, Northwest University for Nationalities \\ Lanzhou (730124), P.R.China, \\ Ixmahaiying8888@163.com
}

Keywords: Higher education; Sino-foreign cooperation; Cross border education; Quality

\begin{abstract}
Since the national education planing, the promulgation and implementation of Chinese-foreign cooperation program of higher education has made many new progress, and gradually enter the high level and high quality development in the new stage. At the same time, the Sino-foreign cooperation program of some deep-seated contradictions and problems have not been solved. At present, the construction of quality has become the new theme of the development of Sino foreign cooperation program. Therefore, combining with the Sino-foreign cooperative education is Chinese education part and innovation to adapt to the development of the new stage of Sino-foreign cooperative education quality concept and quality standards. We focus on the quality of the construction of Sino-foreign cooperation program, and to explore the construction of international standards convergence with Chinese characteristics to ensure the quality and approval to build the access mechanism. The supervision mechanism and punishment evaluation classification authentication mechanism, exit mechanism is the focus of the educational quality.
\end{abstract}

\section{Introduction}

Up to September 2013, there are 1979 national Sino-foreign cooperative education institutions and projects approved by the national examination and approval authorities in China with the total number of students about 550 thousand. Chinese foreign cooperation in running higher education graduates has more than 1.5 million. After more than ten years of development, Sino-foreign cooperation program has become a part of China's education body, which has become one of the main forms of cross-border education in china. Since the promulgation and implementation of the educational plan, a lot of new progress has been made in Sino foreign cooperation program, which has entered a new stage of development with high level and high quality. How to improve the quality of education in Sino foreign cooperation program, expand opening up education, enhance the level of internationalization, become the theoretical problems of educational theorists and practitioners of Sino foreign cooperation program in-depth thinking and practical issues.

\section{The Distinctive Theme of the Quality of Sino-foreign Cooperation Program}

The Demand for the Quality Education and the Trend. the international development of cross-border education, the concept of running a diversified trend. From the traditional point of view, cross-border education provide the country to obtain more economic benefits as the main education concept, such as the United States, Britain, Australia, New Zealand Education exporting countries have outside the cooperative education as their main export industry, in order to obtain more education export trade. With the continuous development of economic globalization and educational internationalization, some foreign educational institutions especially the first-class universities on the one hand, foreign cooperation program emphasize international understanding, strengthen capacity building, human resources development, and pay attention to ensure the quality of education and their own strength enhancement. For example, Sino-US cooperation program of New York University in Shanghai, the tuition income. after deducting the running cost of the York University funded very 
little, because this year the school donated funds up to tens of billions of dollars, and overseas cooperation, facing the problems of education quality and the school because of reputational risk may be affected, the evaluation must be comprehensive and scientific risk. Again, from the Wuhan University, Jiangsu Province, Kunshan municipal government and the Duke University cooperation in the establishment of the Kunshan Duke University, Duke University through cooperative education with aiming to make up the process of internationalization, is hard to beat Harvard regret at home.

More and more international organizations actively advocate and promote cross-border education quality assurance, cross-border education quality guarantee mode and establishing a distinctive, and earnestly safeguard the interests of students has become an important aspect of the attention of all countries in cooperation program. In 2005, the Organization for Economic Cooperation and Development (OECD) jointly formulated the Guideline for Quality Provision in Cross-border Higher Education), designed to support and encourage international cooperation to improve cross-border higher education quality assurance in the understanding of the importance of the protection of students; and other stakeholders from the low quality and non-standard operators violation; also encouraged to meet the development of high-quality cross-border higher education social economic and cultural needs. Some regional international organizations, but also to give a high degree of concern. As to ensure the quality of European Higher Education Network, ENQA was created to promote the European higher education quality assurance cooperation.

The Main progress and Problems of the Quality Construction. Quality is the lifeline of Sino foreign cooperation program. In the practice of Sino foreign cooperation program, all work should be implemented to improve the quality of Chinese foreign cooperation program and improve the quality of personnel training, in order to achieve tangible results. After the promulgation and implementation of the educational plan, the state education administrative department has strengthened the top-level design and quality supervision of Chinese foreign cooperation program. For example, in March 2012, the general office of the Ministry of Education issued on the strengthening of foreign school management, to further clarify the Sino foreign cooperative education policy limits, is currently stepping up research to develop high school Sino foreign cooperative education management guidance and the Sino foreign cooperation program guidance, quality assurance in January 2013, at the conclusion of the 4 province foundation Sino foreign cooperative education pilot assessment experience, launched a new round of Sino foreign cooperative education assessment. At present, Sino foreign cooperation program is gradually entering into a new stage of high level and demonstration development. Some of the good foundation, high starting point of Sino foreign cooperative education institutions and projects approved establishment, a number of "985" and "211" universities with high level Sino-foreign cooperative education and the project of Sino-foreign cooperative play a leading role.

At present, there are still some problems in the cooperation program, such as the Sino-foreign cooperative education institution or project needs to be improved in the overall level and quality of the introduction of educational resources, school behavior of some institutions and projects need to further standardize; discipline structure should be further optimized, the regional distribution and the country where the partners need to further adjust the layout etc.. Generally speaking, the supporting conditions for the construction of Sino-foreign cooperation program are still relatively weak, and some of the policies and measures related to quality construction are short term. These problems are to be solved in the process of the development of Sino foreign cooperation.

\section{Innovating on the Quality Concept of Sino-foreign Cooperation Program.}

Re Understanding of Cooperation in the Construction of Teaching Quality. The accurate orientation of Sino foreign cooperation program is the precondition of quality construction of Sino foreign cooperation program. In 2003, the State Council promulgated the Regulations on Chinese foreign cooperation program. This is a major breakthrough in the supplementary provisions of the former State Education Commission in 1995 on the Sino-foreign cooperation program. The current 
problem is that this position has not yet become a common understanding and action guide, and this is not consistent with the positioning of the wrong understanding and practice is still in some places of Sino foreign cooperation program. At present, many schools do not have to know the Sino foreign cooperation program in the school internationalization strategy, many schools to supplement other schools located in the Sino-foreign cooperation in running school activities, as a means of income, made the school to borrow foreign education resources above their own channels. some universities have taken internationalization, but not the Sino-foreign cooperative education into school management within the Department of international cooperation and exchange.

The main body of Sino-foreign cooperation program is the Chinese and foreign educational institutions, and the way of running schools is the cooperation between the two sides. Chinese educational institutions no substantive introduction of foreign educational resources, only to credit way with foreign educational institutions to carry out educational exchange activities, such as school exchange program and general preparatory classes, unilateral introduction of some foreign educational institutions such as course, do not belong to the Sino foreign cooperative education. At present, there are under the banner of Sino-foreign cooperative education banner in some do not belong to the Sino foreign cooperative education activities, or intentionally or unintentionally confuse the policy limit of Sino foreign cooperative education, the general problems attributed to the exchange activities of Sino foreign cooperation program, all of these, make quality of Chinese foreign cooperation in running the construction of paired interference and confusion.

Establishing the Correct Quality Concept of Sino-foreign Cooperation Program. We should have an objective understanding of the quality of Sino-foreign cooperation program. Viewing from the traditional knowledge of quality, the current Sino foreign cooperation program in the introduction of foreign educational resources and the overall level of quality and the quality of students and teachers quality, Sino-foreign cooperative education institutions and projects are not quality is not high. But the new development stage of education quality evaluation criteria should have international vision, familiar with international rules, to participate in international affairs and international competition, can give full play to the individual, to meet the needs of social development, can make students on the basis of the original is obviously improved.

The national education planning put forward clearly adapting to the national economic and social demands, and cultivate a large number of international talents with international vision, which familiar with international rules to participate in international affairs and international competition. To establish a correct concept of quality of Chinese foreign cooperation program. In the stage of popularization of higher education, the traditional and simple knowledge education in the past is not suitable for the evaluation of the quality of higher education.

\section{Establishing the Quality Assurance Mechanism of Sino-foreign Cooperation Program}

With the deepening of China's education reform and the development of Sino foreign cooperation program, it is urgent to establish a quality assurance system with Chinese characteristics and its operation mechanism. The existing policies and regulations to revise and improve the overall introduction of regulations or policy documents, quality assurance mechanism for the establishment of Sino foreign cooperative education, implementation of regulations and policies and measures of the rigid flexibility combined with the guidance and protection of Sino foreign cooperative education towards high level and high quality development.

Examination and Approval Mechanism. To ensure the quality of the Sino foreign cooperation program, from the source, strengthen the standardized management of Sino foreign cooperative education institutions, to ensure that the introduction of foreign real quality education resources and overseas educational institutions at home and have a good qualification and conditions of cooperation, the establishment of the approval system into the machine is the key link with strictly improvement the access approval mechanism. Is a strict examination and approval, analyze the necessity and feasibility of the review be established or organized by Sino-foreign cooperative education institution 
or project, to further clarify the access standards, a reasonable set of barriers to entry, establishment of pre evaluation system of reporting institutions and projects; two is to further improve the foreign cooperative education institutions for approval of the project leadership system and mechanism. The mechanism to promote the construction of the provincial education administrative departments to declare the project quality, have the ability to control the initiative; three is to further strengthen the provincial education administrative departments of the responsibility consciousness, improve the responsibility system; four is the basic rules and characteristics of education to follow the foreign affairs, steady progress in the Sino foreign cooperation in running and scientific management, the administrative departments of education should be more to strengthen the macro layout and the quality supervision, to take control of the tube thing well.

Classified Supervision Mechanism. To measure the quality of Chinese foreign cooperation program with the same quality standard, the difference will neglect the education institutions and projects, it is difficult to form the distinctive characteristics of the quality assurance, lack of focus, not conducive to the diversification of the quality evaluation of Chinese foreign cooperation program. According to the characteristics of the diversification of Sino-foreign cooperation program, the idea of classified management should be established. Judging from the current situation, the main Sino foreign cooperation to do credit institutions and projects to distinguish between the two categories of management. The Chinese foreign cooperation program is based on whether there is an independent legal person qualification, and is divided into independent set of Sino foreign cooperative universities and two colleges. There are differences between organizational structure and operation mode. Sino-foreign cooperative education institutions set up independently, and it should emphasize the combination and encourage high level university.

Assessing Certification Mechanism. Work has played a certain role in promoting the quality of construction, but there are still formalism and individual fraud phenomenon. On the basis of summing up the experience of the pilot assessment, a new round of Sino-foreign cooperative education quality assessment has been started. From the nature and cycle assessment, the assessment was conducted for Sino-foreign cooperative education institutions and projects conformity assessment, on the basis of the principle of Sino Foreign Cooperative Education approval of the school year and the culture period of regular assessment. Conformity assessment is one of the lowest standards of access mechanism, which is out of touch with the market demand for high-quality educational resources. On the basis of conformity assessment, we should try to establish an excellent evaluation mechanism to promote the construction of high level model of Chinese-foreign cooperative education institutions and projects. From the evaluation body, evaluation of Sino-foreign cooperative education organized by the International Department of the Ministry of education, Ministry of education degrees and graduate education development center, the specific implementation of the specific arrangements, the provincial education administrative departments, and the introduction of the multi evaluation, the formation of the government, society, experts, Chinese and foreign cooperators, students participate in collaborative pattern. The quality evaluation of Chinese foreign cooperation program should play a role in promoting the construction of quality, and we must fundamentally solve the problem of how to evaluate and judge.

Punishment and Exit Mechanism. From the perspective of cross border education, many education importing countries attach great importance to the quality of cross-border education by means of sanctions. In Singapore, for example, cross-border education appears in the form of private education. In order to strengthen the supervision of the form, the Singapore government adopted the private education acts in 2009 (Private Education Act) and the private education regulations, the establishment of mandatory fortification architecture (Enhanced Registration registered Framework, referred to as ERF), requires all private educational institutions (including foreign institutions) in before the operation, must be registered to the Council for private education. It is an offence for any private educational institution or person to publicize the course approved by the Council for private education or to charge fees for such courses to students. If a private educational institution has been 
found guilty of these illegal acts, the registration period may be shortened, and the registration may be suspended or cancelled.

\section{Conclusions}

It is an important direction to establish the guarantee mechanism of Sino-foreign cooperation program. For Sino-foreign cooperative education management, this is a start with a new, meaningful work, innovation of school discipline and school management system and the comprehensive reform of the education sector will play a role in promoting and promoting. How to achieve the system balance and structural adjustment of Chinese foreign cooperation program through the survival of the fittest is the problem to be solved. In 2007, the Ministry of education proposed the establishment of Sino-foreign cooperative education law enforcement and punishment mechanism, but in recent years, the implementation of this requirement is not optimistic. At present, it is necessary to strengthen the research and exploration of the exit mechanism, and gradually establish and improve the exit mechanism. The exit mechanism in the exploration.

\section{Acknowledgements}

This work is supported by Special Funds for Undergraduate Teaching Reform by Central University of Northwest Minzu University (Grant No:10019153 ).

\section{References}

[1] Lin Jinhui, Studying abroad needs special protection to improve the quality of Chinese foreign cooperation program. China Education Newspaper, 2013.

[2] UNESCO/OECD. Guideline for Quality Provision in Cross-border Higher Education[EB/OL] .[2013-9-12]http: //www.

[3] //www.moe.gov.cn/publicfiles/business/htmlfiles/moe/moe_861/201204/xxgk_133915.html.

[4] The general office of the Ministry of education People's Republic of China . Notice of the general office of the Ministry of education to strengthen the standardized management of the foreign school,2013.

[5] Lin Jinhui, Liu Zhiping, Research on Sino foreign cooperative education in higher education. Guangzhou. Guangdong Higher Education Press, 2010.

Pan Maoyuan, The view of educational quality in the popularization of higher education. Chinese Higher Education Research.1 (2000)77-83.

[6] Tang Zhenfu. Research on the construction of quality assurance system of Sino foreign cooperative education in Higher Education of China, Jiangsu Higher Education, 2(2013) 17-25.

[7] [12]Glidden, Robert. The contemporary context of accreditation: Challenges in a changing environment. [EB/OL]. [2013-5-19]. http: //www.chea.org/Events/Usefulness/98May/ 98_05 Glidden. html.

[8] Bikas C. Sanyal and Michaela Martin. Quality assurance and the role of accreditation: an overview.[EB/OL] .[2013-5-19].http: //upcommons.upc.edu/handle/2099/8095.

[9] Gu Jianxin, Xu Hui, Quality assurance, certification and Accreditation of transnational education. Comparative Education Research. 4 (2006) 66-73.

[10] The Ministry of education in People's Republic of China. The Ministry of education on Further Regulating Sino-foreign Cooperation Program, 2013.

[11] He Zubin, Establishment of long term mechanism of teaching quality assurance in higher education institutions in the post evaluation period, China University of Education.3 (2009)69-71.

[12] Liu Hong Wei, Analysis of the current situation and Development Countermeasures of Sino foreign cooperation program, Journal of Jilin Institute of Education. 6 (2006) 89-90. 